\title{
Analysis of adult damselfly fecal material aids in the estimation of antibiotic-resistant Enterobacterales contamination of the local environment
}

\author{
Yuyu Yamaguchi $^{1}{ }^{2}$, Torahiko Okubo $^{2}{ }^{2}$, Mizue Matsshita ${ }^{2}$, Masashi Wataji ${ }^{1}$, Sumio Iwasaki \\ Hayasaka $^{3}$, Kouzi Akizawa ${ }^{3}$, Junji Matsuo ${ }^{2}$, Chikara Shimizu ${ }^{3}$, Hiroyuki Yamaguchi ${ }^{\text {Corresp. }{ }^{2}}$ \\ 1 Hokkaido Sapporo Asahigaoka Senior High School, Sapporo, Japan \\ 2 Department of Medical Laboratory Science, Faculty of Health Sciences, Hokkaido University, Sapporo, Japan \\ 3 Hokkaido University Hospital, Sapporo, Japan \\ Corresponding Author: Hiroyuki Yamaguchi \\ Email address: hiroyuki@med.hokudai.ac.jp
}

Because damselflies are ubiquitously but focally present in natural environments and play a critical role as predators of other insect species, the fecal matter of damselflies may be useful for investigating antibiotic-resistant bacterial populations, including human pathogens, in local environments. We therefore examined the prevalence of antibioticresistant bacteria, including Enterobacterales, in fecal material from 383 damselflies (adults and larvae) collected from seven locations around Sapporo City, Japan, in 2016 and 2017. Fecal samples were plated on soybean casein digest (SCD) agar plates with and without antibiotics (SCD-A and SCD-w/o, respectively) to identify environmental bacteria and gut bacteria, respectively, and on MacConkey agar plates with antibiotics (MacConkeyA) to select for Gram-negative bacteria, including human pathogenic Enterobacterales species. The prevalence of colonies on each of the plates was compared, and representative colonies on MacConkey-A plates were identified to the species level using an API 20E kit and the MALDI Biotyper system. Overall, SCD-w/o plates showed a gut bacterial load of approximately $10^{8}$ colony-forming units per adult damselfly or larva. There was a significant difference between the prevalence of colonies on the SCD-A and MacConkey-A plates, and a significantly increased prevalence of antibiotic-resistant bacteria on MacConkey-A plates was observed in samples collected from Shinoroshinkawa. Cluster analysis based on minimum inhibitory concentration values of 59 representative isolates from MacConkey-A agar plates revealed that samples from Shinoroshinkawa contained a higher prevalence of Enterobacterales than those from other sampling locations. Thus, fecal materials discharged by adult damselflies could be used in future studies as a simple tool for estimating antibiotic-resistant bacteria, including Enterobacterales species, in the local environment. 


\section{Analysis of adult damselfly fecal material aids in the estimation of antibiotic-} resistant Enterobacterales contamination of the local environment

4 Yuyu Yamaguchi ${ }^{1 \#}$, Torahiko Okubo ${ }^{2 \#}$, Mizue Matsushita ${ }^{2}$, Masashi Wataji ${ }^{1}$, Sumio Iwasaki ${ }^{3}$,

5 Kasumi Hayasaka ${ }^{3}$, Kouzi Akizawa ${ }^{3}$, Junji Matsuo², Chikara Shimizu³, Hiroyuki Yamaguchi ${ }^{1 *}$

7 'Hokkaido Sapporo Asahigaoka Senior High School, Asahigaoka, Chuo-ku, Sapporo, Japan.

8 2Department of Medical Laboratory Science, Faculty of Health Sciences, Hokkaido University,

9 Sapporo, Japan.

$10{ }^{3}$ Hokkaido University Hospital, Sapporo, Japan.

12 Running title: Drug-resistant bacteria in damselfly

$14 *$ Corresponding author:

15 Hiroyuki Yamaguchi.

16 E-mail: hiroyuki@med.hokudai.ac.jp

17 \#Y.Y. and T.O. contributed equally to this work

19 E-mail addresses

20 Yuyu Yamaguchi: asahigaoka_seibutubu@yahoo.co.jp

21 Torahiko Okubo: t.okubo@hs.hokudai.ac.jp

22 Mizue Matsshita: mizue.m.may@gmail.com

23 Masashi Wataji: watashi_wataji@yahoo.co.jp 
24 Sumio Iwasaki: sumio55@med.hokudai.ac.jp

25 Kasumi Hayasaka: kasukasu@med.hokudai.ac.jp

26 Kouzi Akizawa: akizawa@med.hokudai.ac.jp

27 Junji Matsuo: matsuo@hoku-iryo-u.ac.jp

28 Chikara Shimizu: shimizch@hotmail.co.jp

29 Hiroyuki Yamaguchi: hiroyuki@med.hokudai.ac.jp

30 


\section{Abstract}

33 Because damselflies are ubiquitously but focally present in natural environments and play a

34 critical role as predators of other insect species, the fecal matter of damselflies may be useful for

35 investigating antibiotic-resistant bacterial populations, including human pathogens, in local

36 environments. We therefore examined the prevalence of antibiotic-resistant bacteria, including

37 Enterobacterales, in fecal material from 383 damselflies (adults and larvae) collected from seven

38 locations around Sapporo City, Japan, in 2016 and 2017. Fecal samples were plated on soybean

39 casein digest (SCD) agar plates with and without antibiotics (SCD-A and SCD-w/o, respectively)

40 to identify environmental bacteria and gut bacteria, respectively, and on MacConkey agar plates

41 with antibiotics (MacConkey-A) to select for Gram-negative bacteria, including human

42 pathogenic Enterobacterales species. The prevalence of colonies on each of the plates was

43 compared, and representative colonies on MacConkey-A plates were identified to the species

44 level using an API 20E kit and the MALDI Biotyper system. Overall, SCD-w/o plates showed a

45 gut bacterial load of approximately $10^{8}$ colony-forming units per adult damselfly or larva. There

46 was a significant difference between the prevalence of colonies on the SCD-A and MacConkey-

47 A plates, and a significantly increased prevalence of antibiotic-resistant bacteria on MacConkey-

48 A plates was observed in samples collected from Shinoroshinkawa. Cluster analysis based on

49 minimum inhibitory concentration values of 59 representative isolates from MacConkey-A agar

50 plates revealed that samples from Shinoroshinkawa contained a higher prevalence of

51 Enterobacterales than those from other sampling locations. Thus, fecal materials discharged by

52 adult damselflies could be used in future studies as a simple tool for estimating antibiotic-

53 resistant bacteria, including Enterobacterales species, in the local environment. 
56

57 The pandemic of multidrug-resistant (MDR) pathogens and their continuing spread is a growing

\section{Introduction}

global concern that represents an immeasurable threat to hospitals and other healthcareassociated facilities (Magiorakos et al., 2012; Hawkey, 2015; Medina and Pieper, 2016). The United States Centers for Disease Control and Prevention reported that there were more than 2 million cases of infection caused by MDR bacteria in the United States, resulting in approximately 23,000 deaths $(C D C, 2012$; Johnson et al., 2014). In addition, the European Centre for Disease Prevention and Control, the European Food Safety Authority, and the European Medicines Agency have identified an increase in the mortality rates associated with infections caused by MDR bacteria in both Asia and Africa (De Beer et al., 2014). As a result, the World Health Organization called on all member countries to promote rational antibiotic use to prevent the spread of antimicrobial resistance (World Health Organization, 2007). However, the lack of a comprehensive management protocol encompassing livestock, circulating food, public hygiene practices, and monitoring of natural environments has resulted in the failure to control the emergence of MDR bacteria (World Health Organization, 2007; CDC, 2012; Magiorakos et al., 2012; Calistri et al., 2013; De Beer et al., 2014; Johnson et al., 2014; Hawkey, 2015; Medina and Pieper, 2016). Hence, a "One Health" approach has been proposed, which would play a crucial role in controlling the emergence of MDR bacteria. Also, it is therefore that appropriate monitoring the emergence of MDR bacteria in particular into natural environments would be critically important for understanding spread of the bacteria, responsible for these control in public health.

Damselflies ubiquitously but focally inhabit natural environments such as rivers and ponds in 


\section{Materials and Methods}

\section{Antibiotics \\ Antibiotics} City, Japan.

\section{Sample collection}

most places around the world (Bourret et al., 2012; Dolný et al., 2012; Dolný et al., 2014; BallDamerow et al., 2015). Because damselflies can be very sensitive to subtle changes in their environment, they may be a good indicator of environmental health and biodiversity (Oliver et al., 2010; Kutcher et al., 2014). Damselflies play a critical role as predators of other small insect species sometimes hatched out around human living sites, many of where contain a lot of microbes, including human pathogens (Siepielski et al., 2011). It is therefore likely that fecal materials discharged by damselflies could be used to examine populations of antibiotic-resistant bacteria, including Enterobacterales species, derived from humans in the local environment. To assess this possibility from the "One Health" viewpoint, we determined the prevalence of antibiotic-resistant Enterobacterales species in the fecal matter of damselflies captured from public places surrounding local rivers and ponds within distinct natural environments in Sapporo

All antimicrobial agents, including cefotaxime (CTX), ampicillin (AMP), kanamycin (KAN), tetracycline (TET), chloramphenicol (CHL), ciprofloxacin (CIP), and sulfapyridine (SPY), were purchased from Sigma-Aldrich. In addition, we selected representative antibiotics that are used as the major veterinary and/or human pharmaceuticals in Japan (Yamasaki et el., 2016).

A total of 315 adult damselflies were captured from June-August 2016 and in June 2017 using an insect net. The damselflies were collected from seven locations: Higashitonden (north latitude: 43.147353; east longitude: 141.337327), Shinoroshinkawa (north latitude: 43.120752; 
102 east longitude: 141.415881), Ohno (north latitude: 43.074279; east longitude: 141.341688),

103 Shinoro (north latitude: 43.159162; east longitude: 141.364069), Tonneusu (north latitude:

104 43.169276; east longitude: 141.408628), Gotenzan (north latitude: 43.048401; east longitude:

105 141.258540), and Yasuharu (north latitude: 43.144301; east longitude: 141.315791). Each

106 sampling site was located near a local river or pond with distinct natural environments in

107 Sapporo City, Japan (Fig. 1). In specific, the most urban location was "Pond: Ohno", located

108 within the grounds of Hokkaido University, near Sapporo Station, in the center of the city (Fig 1.

109 See "Green density"). In contrast, the "River: Gotenzan" sampling site was located in a forest

110 and was therefore the most "natural" of the sampling locations (Fig 1. See "Green density").

111 Sixty-eight larvae were also collected from three of the locations (Shinoroshinkawa, Tonneusu,

112 and Yasuharu) in June 2017 (Fig. 1). Environmental temperatures at each of the sampling

113 locations were obtained from the Japan Weather Association (http://www.tenki.jp/).

114 Species determination for the captured adult damselflies

115 The species of each of the captured adult damselflies was determined morphologically based on

116 distinguishing colors and patterns (lines and spots) on the body and wing (See Fig. 2A). Because

117 of the difficulties associated with morphological species determination of larvae, the species of

118 damselfly larvae samples could not be identified.

119 Collection of fecal materials

120 Fecal samples were collected as per the protocol outlined in Fig. 3. Briefly, adult damselflies

121 wrapped in clean paper, along with larvae that had been immersed in sterile phosphate-buffered

122 saline (sPBS) after washing with sPBS to prevent contamination from the exoskeleton, were

123 stored at room temperature for at least a week. Dead individuals were omitted from the

124 subsequent experiments. Fecal materials discharged onto the paper or into the sPBS were 
125 collected into fresh sPBS solution and homogenized. Aliquots of the homogenized solutions

126 were inoculated onto soybean casein digest (SCD) agar plates (BD Biosciences) minus

127 antibiotics (SCD-w/o) as an indicator of total damselfly gut bacteria, SCD agar plates

128 supplemented with CTX (50 mg/liter) or TET $(50 \mathrm{mg} / \mathrm{liter})$ (SCD-A) as an indicator of

129 environmental bacteria that frequently resist to these antibiotics (Huang et al., 2015), and

130 MacConkey agar plates supplemented with AMP (10 mg/liter), TET (10 mg/liter), or KAN (10

$131 \mathrm{mg} / \mathrm{liter}$ ) (MacConkey-A) as an indicator of Gram-negative bacteria, including human-derived

132 pathogenic Enterobacterales species. All plates were incubated at $25^{\circ} \mathrm{C}$ before colony

133 enumeration to prevent over growth on agar plates covered by environmental bacteria

134 characteristic of rapid growth above $30^{\circ} \mathrm{C}$ temperature. Results were then expressed as colony-

135 forming units (CFU) per individual damselfly or larva. Any SCD-A or MacConkey-A plate with

136 more than one colony was considered positive for antibiotic-resistant bacteria, followed by

137 comparing these prevalence among sampling sites; the prevalence is defined to be the number of

138 sample showing agar plates (SCD-A or MacConkey-A plate) with more than one colony.

139 Morphologically representative colonies on MacConkey-A plates were also isolated and used for

140 antimicrobial susceptibility testing according to the method described below.

\section{Bacterial species determination}

142 Bacterial species were identified using an API 20E kit according to the manufacturer's protocol

143 (bioMérieux). The MALDI Biotyper system (Bruker Daltonics) was used as per the

144 manufacturer's instructions to identify those species that could not be determined using the API

145 kit. Meanwhile, if the API value was low (below 80\%), bacterial 16S rDNA typing was

146 performed to define bacterial species according to the protocol described previously (Horn et al.,

147 1999). 
148 Antimicrobial susceptibility testing

149 Antimicrobial susceptibility testing was performed for each of the identified bacterial isolates

150 using the agar-dilution method to determine the minimum inhibitory concentration (MIC) values

151 for six antimicrobial agents (AMP, KAN, TET, CHL, CIP, and SPY) on Mueller-Hinton II agar

152 (BD Biosciences). Assays were carried out according to the criteria determined by the CLSI

153 (Wiegand et al., 2008). Staphylococcus aureus ATCC29213 and Escherichia coli ATCC25922

154 were used as quality control strains.

155 Clustering and phylogenic analysis

156 Cluster analysis was performed using Cluster 3.0 for Mac OS X (Clustering Library 1.52) as

157 described previously (Okubo et al., 2017). Phylogenetic trees were generated from the aligned

158 population structures by Cluster 3.0 (See below) and visualized in Java TreeViewX (version

159 0.5.0). Specifically, the obtained data were transformed to a log scale, and then processed with

160 the setting [ $>80 \%$ filtering and Pearson correlation (centered)]. While the data associated with

161 specific variables (temperature, total bacterial numbers on SCD-w/o, the prevalence of bacteria

162 on SCD-A, the prevalence of bacteria on MacConkey-A were converted to an equivalent range

163 (0-1), the MIC data were used without any alterations. The resulting data were then processed

164 using the setting ( $>80 \%$ filtering and Spearman rank correlation) and converted to "cdt" files

165 using Cluster 3.0 then visualized using TreeViewX.

166 Ethics

167 The study reported in this manuscript did not involve any human participants, human data,

168 human tissue, data pertaining to specific individuals, or animal experiments.

169 Statistical analysis 
170 Comparison of total CFU numbers between sampling locations was conducted using a

171 Bonferroni/Dunn test. A $p$-value of $<0.01$ was considered significant. Correlations among factors

172 (temperature, total bacterial numbers on SCD-w/o, the prevalence of bacteria on SCD-A, the

173 prevalence of bacteria on MacConkey-A) were identified by Pearson's correlation coefficient

174 test. A correlation coefficient value of $>0.5$ or $<-0.05$, with a $P$-value of $<0.05$, was considered

175 significant. Comparisons between the prevalence of bacteria on SCD-A and MacConkey-A agar

176 plates were conducted using a Chi-square for independence test. Comparisons between the

177 prevalence of antibiotic-resistant isolates obtained from MacConkey-A plates at each of the

178 sampling locations were also conducted using a Chi-square for independence test. A combination

179 with a $P$-value of $<0.05$ was considered statistically significant. All calculations were conducted

180 using Excel for Mac (2001) with Statcel3C.

\section{Results}

\section{Damselflies are ubiquitously but focally present in local environments}

184 Because our study relied on the domestic behaviors of damselflies at each location, we first

185 assessed whether focal inhabitation by adult damselflies could be observed at each of the

186 sampling sites. A total of 315 adult damselflies were captured between June and August 2016,

187 and in June 2017, at seven locations (Fig. 1). Morphological species identification results for the

188 captured adult damselflies are summarized in Fig. 2A. Although all sampling sites were located

189 within a $10-\mathrm{km}^{2}$ area, the prevalence of each of the 11 identified damselfly species varied

190 between the sites (Fig. 2B). Coenagrion ecornutum was the most dominant species at the "River:

191 Higashitonden" location, while Enallagma circulatum was most commonly identified at the 
192 "River: Shinoroshinkawa", "River: Shinoro", and "Marsh: Tonneusu" sites. The dominancy of

193 Paracercion hieroglyphicum was higher at the "River: Yasuharu" and "Marsh: Tonneusu" sites

194 compared with the other locations, while Lestes sponsa was more frequently identified at the

195 "River: Gotenzan" site compared with all other sampling sites. In addition, 68 damselfly larvae

196 were collected from three of the sampling sites (Shinoroshinkawa, Tonneusu, and Yasuharu) in

197 June 2017. However, morphological species identification was not possible for the larvae. Thus,

198 as expected, the population density of adult damselflies changed depending on the sampling

199 location, indicating that damselflies ubiquitously but focally inhabit each of the local

200 environments around Sapporo City.

201

202 Relationship between temperature and total number of bacteria in the damselfly gut and

203 the prevalence of antibiotic-resistant bacteria

204 Fecal materials from both adult and larval damselflies were collected, and the bacterial numbers

205 were estimated according to the protocol outlined in Fig. 3. When estimated using SCD-w/o

206 medium, the total number of bacteria per adult/larval damselfly was fairly consistent across all

207 sampling locations ( $10^{8}$ CFU per adult/larva), except for the "Pond: Ohno" site (Fig. 4). We

208 also assessed the relationship between the total bacterial load (SCD-w/o) or the prevalence of

209 antibiotic-resistant bacteria (SCD-A and MacConkey-A plates) and environmental temperature

210 using a Pearson's correlation coefficient test and cluster analysis with a Spearman's correlation

211 coefficient by rank test. The results showed that temperature changes were significantly but

212 negatively correlated with the total bacterial load on SCD-w/o plates ( $r$ coefficient -0.677 vs.

213 "Lowest temperature", $P<0.0001 ; r$ coefficient -0.590 vs. "Highest temperature", $P<0.0001$ )

214 (Fig. 5A). Meanwhile, no significant correlation between temperature changes and the 
215 prevalence of colonies on SCD-A and MacConkey-A agar plates was observed. Furthermore,

216 cluster analysis based on three different indicators (environmental temperature, total bacterial

217 numbers in fecal samples, the prevalence of antibiotic resistant bacteria) revealed several clades

218 grouped by sampling location (Fig. 5B, blue bars). Interestingly, samples obtained from the

219 "River: Shinoroshinkawa" site were assigned to two different groups, which, together, had the 220 highest prevalence of antibiotic resistant bacteria (Fig. 5B, red bars with asterisks). Thus, while

221 the fecal bacterial load on SCD-w/o medium was fairly constant and was negatively correlated 222 with environmental temperature, the prevalence of antibiotic-resistant bacteria changed 223 depending on the sampling location and was not related to environmental temperature.

Prevalence of antibiotic-resistant bacteria and identification of representative antibioticresistant Enterobacterales

227 To determine which antibiotic-resistant bacterial strains were most prevalent in the sampled environments, we estimated the prevalence of antibiotic-resistant bacteria in the damselfly fecal samples. SCD-A medium was used as an indicator of environmental bacteria, while MacConkeyA medium was used to select for pathogenic bacteria, including Enterobacterales, derived from humans. Results showed that the prevalence of environmental and human-derived pathogenic bacteria changed depending on the sampling site, irrespective of whether the samples came from adult or larval damselflies (Table S1). However, at almost all sampling locations, environmental antibiotic-resistant bacteria were significantly more prevalent than human-derived pathogenic bacteria (adult damselfly: "River: Shinoro", $P=0.0487$; "Marsh: Tonneusu”, $P<0.0001$; larvae:

"River: Yasuharu", $P=0.0329$; "Marsh: Tonneusu", $P<0.0001)$. Interestingly, the samples 
238 resistant human-derived pathogenic bacteria $(P=0.0149)$. Thus, the results revealed that the

239 prevalence of antibiotic-resistant bacteria in the fecal materials of both adult and larval

240 damselflies significantly differed between sampling sites, reflecting differences in bacterial

241 contamination of each of the domestic environments.

242

243 Amongst the sampling locations, the "River: Shinoroshinkawa" site appeared to be statistically

244 unique, with an increased prevalence of antibiotic-resistant Enterobacterales on MacConkey-A

245 plates. To confirm this, 59 representative antibiotic-resistant Enterobacterales isolates from adult

246 damselfly fecal material were selected from MacConkey-A plates and identified using an API kit

247 and the MALDI Biotyper system with MIC assessments (Table S2). The predominant bacterial

248 species identified were Serratia fonticola, Serratia liquefaciens, Enterobacter aerogenes,

249 Enterobacter cloacae, Klebsiella oxytoca, and Stenotrophomonas maltophilia. As expected, the

250 site with the highest prevalence of antibiotic-resistant bacteria was "River: Shinoroshinkawa" $\left(\chi^{2}\right.$

251 test: $p<0.001$ ) (Fig. 6). The MICs $\left(\mathrm{MIC}_{50}\right.$ and $\left.\mathrm{MIC}_{90}\right)$ of AMP, KAN, TET, CHL, CIP, and SPY

252 for each of the identified bacteria were also determined and used as a basis for clustering analysis

253 (Table S1). Although there were no obvious differences in the MIC ranges between the sampling

254 sites except for Shinoroshinkawa with high values of MIC90 for KAN and CIP (Fig. 7A), cluster

255 analysis revealed that the identified bacteria derived from the "River: Shinoroshinkawa" site

256 formed a cluster and showed higher MIC values and a greater prevalence of multidrug resistance

257 compared with other sampling locations (Fig. 7B). Thus, the "River: Shinoroshinkawa" site was

258 unique amongst the sampling locations, with the highest frequency of antibiotic-resistant

259 Enterobacterales. 


\section{Discussion}

262 Seven distinct locations (Higashitonden, Shinoroshinkawa, Ohno, Shinoro, Tonneusu, Gotenzan, 263 and Yasuharu) around Sapporo City, Japan, were selected as sampling sites. All sampling sites 264 were located within an $\sim 10-\mathrm{km}^{2}$ area, and demonstrated distinct environmental conditions 265 ranging from natural to urban. Although the sampling sites were geographically close, the 266 prevalence of different damselfly species differed significantly between the sampling sites, with 26711 species of damselfly identified across all locations. These differences confirmed the validity 268 of the sampling site selections. In particular, the damselfly population at the "River: Gotenzan" 269 location was unique amongst the sampling sites, with a simple population of $L$. sponsa. This site 270 was located at the highest altitude of all the sampling locations, which may account for the 271 limited population. Thus, our findings agree with previous studies (Bourret et al., 2012; Dolný et 272 al., 2012; Dolný et al., 2014; Ball-Damerow et al., 2015) showing that damselflies focally and 273 domestically inhabit a particular location, with minimal migration between sampling sites.

275 Analyses using SCD-w/o medium revealed a total bacterial load of $\sim 10^{8} \mathrm{CFU}$ per adult 276 damselfly or larva at all sampling sites, except for "Pond: Ohno". The "Pond: Ohno" site was 277 located upstream of a river and contained little organic matter that would support environmental 278 bacteria, perhaps resulting in a lower bacterial load in insects at this location. Meanwhile, the 279 number of bacteria in larval fecal matter was significantly higher than that in adult damselflies, 280 reflecting the fact that pond and river water contains a much higher level of organic matter that 281 can support fungal prosperity as well as bacterial growth. It is interesting to note that estimation 282 of total bacterial numbers failed in some larval samples with fungal contamination. In addition, 283 because damselflies mature through incomplete metamorphosis (Abbott and Svensson, 2005), 
284 very few of the gut bacteria present in larvae are transferred to the gut of the adult damselfly.

285 Thus, the fecal bacterial load estimated using SCD-w/o plates can be used as an indicator of 286 damselfly gut bacteria.

287

288 We found that changes in environmental temperature were significantly but negatively correlated 289 with total bacterial load on SCD-w/o plates. This may indicate that increases or decreases in 290 temperature causes stress, thereby impairing insect growth (Leitch and Ceballos, 2008). This 291 would correlate with the observed decreases in total bacterial numbers in fecal materials with 292 increasing environmental temperature, which was reflected by changes in the gut bacteria. 293 Meanwhile, no significant correlation was found between temperature changes and the 294 antibiotic-resistant bacterial load on SCD-A and MacConkey-A agar plates. It is therefore likely 295 that the prevalence of these bacteria reflects the food intake of the damselflies, which consists of 296 small insects domestically inhabiting each of the sampling locations. In addition, as the cluster 297 analysis based on different indicators (environmental temperature, total bacterial numbers in 298 fecal samples, the prevalence of antibiotic-resistant bacteria) revealed several clades grouped by 299 sampling location, we conclude that these combinations of indicators can be used to characterize 300 traits of each of the sampling locations to determine actual environmental contamination by 301 antibiotic-resistant bacteria. Thus, damselfly fecal samples can be used to monitor the prevalence 302 of antibiotic-resistant bacteria in local environments.

304 The predominant bacterial species with antibiotic-resistance isolated from damselfly's fecal 305 materials were Serratia fonticola, , Serratia liquefaciens, Enterobacter aerogenes, Enterobacter 306 cloacae, Klebsiella oxytoca, and Stenotrophomonas maltophilia, all of which are opportunistic 
307 pathogens as causative agents response for pneumonia, urinary tract infection or septicemia in

308 compromised host. Although there was no evidence showing any direct contact of these

309 pathogens in damselfly's feces to human on infectious diseases, it is likely that the pathogens

310 have an impact on maintaining human health in urban environments.

312 Cluster analysis based on MIC data revealed that the identified bacteria derived from the "River:

313 Shinoroshinkawa" site formed a distinct cluster and had higher MIC values than bacteria isolated

314 from other locations. At the present time, the reason for these higher MIC values remains

315 unknown. However, two miniature golf courses are located close to the "River Shinoroshinkawa"

316 sampling site. Historically, large quantities of herbicides and/or pesticides have been used on

317 golf courses to maintain the lawns. It is therefore possible that herbicides or pesticides have

318 induced cross-resistance to antibiotics in environmental bacteria at the "River Shinoroshinkawa"

319 site. This is supported by the fact that acetolactate synthase-inhibiting herbicides and

320 nitrophenolic herbicides can induce cross-resistance to antibiotics in environmental bacterial

321 species with similarities to fungi (Elanskaya et al., 1998; Plaza et al., 2003; Snelders et al.,

322 2012). In addition, antibiotic-resistant Enterobacterales were only isolated from damselflies, not

323 from larvae. Although the exact reason remains unknown, it is apparent that the flying predation

324 of damselflies is a key factor in the accumulation of antibiotic-resistant bacteria in the gut

325 through the capture of small insects such as flies. Therefore, damselflies are potential vectors in

326 terms of spreading antibiotic-resistant human pathogenic bacteria. Furthermore, animal or birds

327 fed on damselfly would have physically important role responsible for migrating bacteria

328 inhabited into the gut, involving to spreading human important Enterobateriales seen in

329 damselflies with minimal migration. 


\section{Conclusions}

332 The present study includes several important findings. First, damselflies focally and domestically 333 inhabit each of the sampling locations, with minimal migration among these areas. Second, the

334 fecal bacterial load, estimated using SCD-w/o medium, can be used as an indicator of damselfly 335 gut bacterial content, thereby reflecting the local ecology at a site. Third, the prevalence of 336 antibiotic-resistant bacteria, estimated using MacConkey-A medium, can be used to monitor 337 antibiotic-resistant bacterial contamination of a location, including Enterobacterales strains that 338 are presumably derived from humans. Taken together, we conclude that adult damselfly fecal 339 material can be used as a simple tool to monitor domestic antibiotic-resistant bacterial pollution, 340 particularly those strains associated with human health. However, this study is limited by the

341 small number of environmental samples and the lack of samples from other sources, such as soil.

342 In addition, there is no similar data from other areas that can be used to independently verify our 343 results. Therefore, further studies using additional environmental samples from more diverse 344 locations are needed to confirm our findings.

\section{Acknowledgments}

347 We thank Tamsin Sheen, PhD, from Edanz Group (www.edanzediting.com/ac) for editing a draft 348 of this manuscript. 


\section{References}

351 Abbott, J., Svensson, E.I. 2005. Phenotypic and genetic variation in emergence and development

352 time of a trimorphic damselfly. J Evol Biol 18(6):1464-1470. DOI:10.1111/j.1420$3539101.2005 .01019 . x$

354 Ball-Damerow, J.E., Oboyski, P.T., Resh, V.H. 2015. California dragonfly and damselfly

355 (Odonata) database: temporal and spatial distribution of species records collected over the 356 past century. Zookeys 482:67-89. DOI:10.3897/zookeys.482.8453

357 Bourret, A., McPeek, M.A., Turgeon, J. 2012. Regional divergence and mosaic spatial 358 distribution of two closely related damselfly species (Enallagma hageni and Enallagma 359 ebrium). J Evol Biol 25(1):196-209. DOI:10.1111/j.1420-9101.2011.02418.x

360 Calistri, P., Iannetti, S., Danzetta, M.L., Narcisi, V., Cito, F., Sabatino, D.D., Bruno, R., Sauro,

361 F., Atzeni, M., Carvelli, A., Giovannini, A. 2013. The components of 'One World - One 362 Health’ approach. Transbound Emerg Dis Suppl 2: 4-13. DOI: $\quad$ 10.1111/tbed.12145

363 CDC. Active Bacterial Core Surveillance Methodology. 2012. http://www.cdc.gov/abcs/index 364. html.

365 De Beer, J.L., Kodmon, C., van der Werf, M.J., van Ingen, J., van Soolingen, D.; ECDC MDR-

366 TB Molecular Surveillance Project Participants. 2014. Molecular surveillance of multi- and 367 extensively drug-resistant tuberculosis transmission in the European Union from 2003 to 2011. 368 Eurosurveillance 19(11):pii20742.

369 Dolný, A., Harabiš, F., Bárta, D., Lhota, S., Drozd, P. 2012. Aquatic insects indicate terrestrial 370 habitat degradation: changes in taxonomical structure and functional diversity of dragonflies

371 in tropical rainforest of East Kalimantan. Tropical Zoology 25(3):141-157. 372 DOI:10.1080/03946975.2012.717480 
373 Dolný, A., Harabiš, F., Mižičová, H. 2014. Home range, movement, and distribution patterns of

374 the threatened dragonfly Sympetrum depressiusculum (Odonata: Libellulidae): a thousand

375 times greater territory to protect? PLoS One 9(7):e100408. DOI:

$376 \quad$ 10.1371/journal.pone.0100408.

377 Elanskaya, I.V., Chesnavichene, E.A., Vernotte, C., Astier, C. 1998. Resistance to nitrophenolic

378 herbicides and metronidazole in the cyanobacterium Synechocystis sp. PCC 6803 as a result

379 of the inactivation of a nitroreductase-like protein encoded by $\operatorname{drgA}$ gene. FEBS Lett

$380 \quad$ 428(3): 188-192. DOI:10.1016/S0014-5793(98)00528-6

381 Hawkey, P.M. 2015. Multidrug-resistant Gram-negative bacteria: a product of globalization. $J$

382 Hosp Infect 89(4):241-247. DOI:10.1016/j.jhin.2015.01.008

383 Horn, M., Fritsche, T.R., Gauton, R.K., Schleifer, K.H. and Wagner, M. 1999. Novel bacterial

384 endosymbionts of Acanthamoeba spp. related to the Paramecium caudatum symbiont

385 Caedibacter caryohilus. Environ Microbiol 1(4):357-367. DOI: org/10.1046/j.1462-

$386 \quad 2920.1999 .00045 . x$

387 Huang, Y., Zhang, L., Tiu, L., Wang, H.H. 2015. Characterization of antibiotic resistance in

388 commensal bacteria from an aquaculture ecosystem. Front Microbiol 6:914. DOI: $389 \quad 10.3389 /$ fmicb.2015.00914.

390 Johnson, N.B., Hayes, L.D., Brown, K., Hoo, E.C., Ethier, K.A.; Centers for Disease Control and

391 Prevention (CDC). 2014. CDC National Health Report: leading causes of morbidity and

392 mortality and associated behavioral risk and protective factors--United States, 2005-2013.

$393 \quad M M W R$ Suppl 63(4):3-27.

394 Kutcher, T.E., Bried, J.T. 2014. Adult Odonata conservatism as an indicator of freshwater 395 wetland condition. Ecological Indicators 38:31-39. DOI:10.1016/j.ecolind.2013.10.028 
396 Leitch, G.J., Ceballos, C. 2008. Effects of host temperature and gastric and duodenal

397 environments on microsporidia spore germination and infectivity of intestinal epithelial cells.

$398 \quad$ Parasitol Res 104(1):35-42. DOI:10.1007/s00436-008-1156-4.

399 Magiorakos, A.P., Srinivasan, A., Carey, R.B., Carmeli, Y., Falagas, M.E., Giske, C.G., Harbarth, $400 \quad$ S., Hindler, J.F., Kahlmeter, G., Olsson-Liljequist, B., Paterson, D.L., Rice, L.B., Stelling, J., 401 Struelens, M.J., Vatopoulos, A., Weber, J.T., Monnet, D.L. 2012. Multidrug-resistant, 402 extensively drug-resistant and pandrug-resistant bacteria: an international expert proposal for 403 interim standard definitions for acquired resistance. Clin Microbiol Infect 18(3):268-281. $404 \quad$ DOI:10.1111/j.1469-0691.2011.03570.x.

405 Medina, E., Pieper, D.H. 2016. Tackling Threats and Future Problems of Multidrug-Resistant 406 Bacteria. Curr Top Microbiol Immunol 398:3-33. DOI:10.1007/82_2016_492.

407 Okubo, T., Osaki, T., Nozaki, E., Uemura, A., Sakai, K., Matushita, M., Matsuo, J., Nakamura, 408 S., Kamiya, S., Yamaguchi, H. 2017. Walker occupancy has an impact on changing airborne 409 bacterial communities in an underground pedestrian space, as small-dust particles increased 410 with raising both temperature and humidity. PLoS One 12(9):e0184980. DOI: $411 \quad$ 10.1371/journal.pone.0184980.

412 Oliver, T., Roy, D.B., Hill, J.K., Brereton, T., Thomas, C.D. 2010. Heterogeneous landscapes 413 promote population stability. Ecol Lett 13(4):473-484. DOI:10.1111/j.1461$414 \quad$ 0248.2010.01441.x.

415 Plaza, G., Osuna, M.D., De Prado, R. 2003. Cross resistance to ALS-inhibiting herbicides in 416 Euphorbia heterophylla L. biotypes resistant to imazethapyr. Commun Agric Appl Biol Sci $417 \quad$ 68(4 Pt A):335-339.

418 Siepielski, A.M., Mertens, A.N., Wilkinson, B.L., McPeek, M.A. 2011. Signature of ecological 
419 partitioning in the maintenance of damselfly diversity. J Anim Ecol 80(6): 1163-1173. $420 \quad$ DOI:10.1111/j.1365-2656.2011.01863.x.

421 Snelders, E., Camps, S.M., Karawajczyk, A., Schaftenaar, G., Kema, G.H., van der Lee, H.A., 422 Klaassen, C.H., Melchers, W.J., Verweij, P.E. 2012. Triazole fungicides can induce cross423 resistance to medical triazoles in Aspergillus fumigatus. PLoS One 7(3):e31801. 424 DOI:10.1371/journal.pone.0031801.

425 Wiegand, I., Hilpert, K., Hancock, R.E. 2008. Agar and broth dilution methods to determine the 426 minimal inhibitory concentration (MIC) of antimicrobial substances. Nat Protoc 3(2):163-175. 427 DOI:10.1038/nprot.2007.521.

428 World Health Organization. 2007. World Health Assembly Resolutions: 51.17/1998, emerging 429 and other communicable diseases: antimicrobial resistance; 58.27/2005 improving the 430 containment of antimicrobial resistance; 60.16/ Progress in the Rational Use of Medicines, 431 Including Better Medicines for Children, Geneva, Switzerland: WHO (2007).

432 Yamasaki, D., Tanabe, M., Muraki, Y., Kato, G., Ohmagari, N., Yagi, T. 2018. The first report 433 of Japanese antimicrobial use measured by national database based on health insurance claims 434 data (2011-2013): comparison with sales data, and trend analysis stratified by antimicrobial 435 category and age group. Infection 46(2): 207-214. DOI: 10.1007/s15010-017-1097-x. 
Figure 1 Map showing sampling locations around Sapporo City, Hokkaido, Japan. Image obtained from Google Maps (https://www.google.co.jp/maps). Arrows show sampling locations: Higashitonden (north latitude: 43.147353; east longitude: 141.337327), Shinoroshinkawa (north

441 latitude: 43.120752; east longitude: 141.415881), Ohno (north latitude: 43.074279; east 442 longitude: 141.341688), Shinoro (north latitude: 43.159162; east longitude: 141.364069),

443 Tonneusu (north latitude: 43.169276; east longitude: 141.408628), Gotenzan (north latitude: 444 43.048401; east longitude: 141.258540), and Yasuharu (north latitude: 43.144301; east 445 longitude: 141.315791).

446

447 Figure 2 Representative images showing distinct morphological traits of damselflies and 448 changes in the dominancy of different damselfly species at each sampling site. (A) 449 Representative images showing distinct morphological traits of damselflies. (B) The dominancy 450 of different damselfly species differed between sampling sites, with a total of 11 species 451 identified across all sites. The y-axis shows the dominancy of damselfly species as a ratio (\%).

453 Figure 3 Collection of fecal materials from adult and larval damselflies and cultures. 1)

454 Collection of fecal materials expelled by adult damselflies wrapped in clean paper, and from 455 larvae in sPBS solution. 2) Culturing of bacteria from fecal materials on SCD agar with or 456 without antibiotics and on MacConkey agar plates with antibiotics. 3) Statistical analysis (See 457 "Materials and Methods"). 
460 without antibiotics. Upper graph shows total bacterial numbers (CFU) in samples from adult 461 and larval damselflies. Lower panel shows results of statistical analyses performed to compare 462 results among sampling locations. Comparisons of the total CFU counts among sampling 463 locations were conducted using a Bonferroni/Dunn test. Closed and open circles show statistical 464 significance at $P<0.01$ and $P<0.05$, respectively.

Figure 5 Association between total bacterial load (SCD agar without antibiotics) or the prevalence of antibiotic-resistant bacteria (SCD agar and MacConkey agar, both with antibiotics) and environmental temperature. (A) Correlations among factors identified using Pearson's correlation coefficient test. A correlation coefficient value of $>0.5$ or $<-0.05$, with a $P$-value of $<0.05$, was considered significant. Blue and red indicate a positive or negative correlation with statistical significance, respectively. (B) Cluster analysis based on the above

472 indicators (environmental temperature, total bacterial numbers in fecal samples, the prevalence 473 of antibiotic-resistant bacteria), with several clades grouped by each of the sampling locations. 474 Blue bars show clusters containing samples from the same location. Red asterisks show "River: 475 Shinoroshinkawa", which had the highest frequency of emerging antibiotic-resistant bacteria. "SCD_CFU/ml" shows the number of total colonies per sample. "SCD-Antibiotics" and "McAntibiotics" show the bacterial growth on SCD-A and MacConkey-A plates, respectively. Also, "SCD-Mc-all antibiotics" shows total frequency of "SCD-Antibiotics" plus "Mc-Antibiotics".

Figure 6 Prevalence of isolates selected on MacConkey agar plates containing antibiotics at 
482 between the prevalence of antibiotic-resistant isolates at each of the sampling sites were 483 conducted using a Chi-square for independence test. Antibiotic-resistant bacteria were most 484 prevalent at the "River: Shinoroshinkawa" site, with statistical significance at $P<0.01$.

485

486 Figure 7 Comparison of the prevalence of antibiotic-resistant bacteria on SCD agar plates 487 with that on MacConkey agar plates, and identification of representative antibiotic488 resistant Enterobacterales, including MIC data. (A) Antimicrobial susceptibility testing results 489 for each of the isolates $\left(\mathrm{MIC}_{50}\right.$ and $\mathrm{MIC}_{90}$ ) for six antimicrobial agents (AMP, KAN, TET, CHL, 490 CIP, and SPY). Isolates were tested using the agar-dilution method on Muller-Hinton II agar 491 medium (BD Biosciences) according to the criteria determined by the CLSI (Wiegand et al., 492 2008). (B) Cluster analysis based on MIC data. The identified bacteria derived from the "River: 493 Shinoroshinkawa" site formed a distinct cluster and had higher MIC values than isolates 494 obtained from other locations. Yellow coloring indicates MIC values for isolates derived from 495 "River: Shinoroshinkawa". 
499 Supporting information

500

501 Table S1: Comparison of the prevalence of antibiotic-resistant bacteria on SCD agar plates

502 with that on MacConkey agar plates.

503

504 Table S2: Results of bacterial speciesis identified by API and/or MALDI biotyper with 16S

505 rDNA typing and thire MICs against AMP (Ampicillin), KAM (Kanamycin), TET

506 (Tetracycline), CHL (Chloramphenicol), CIP (Ciprofloxacin) and SPY (Sulfapyridine).

507

508 
Figure 1

Map showing sampling locations around Sapporo City, Hokkaido, Japan. The image was obtained from Google Maps (https://www.google.co. jp/maps). 

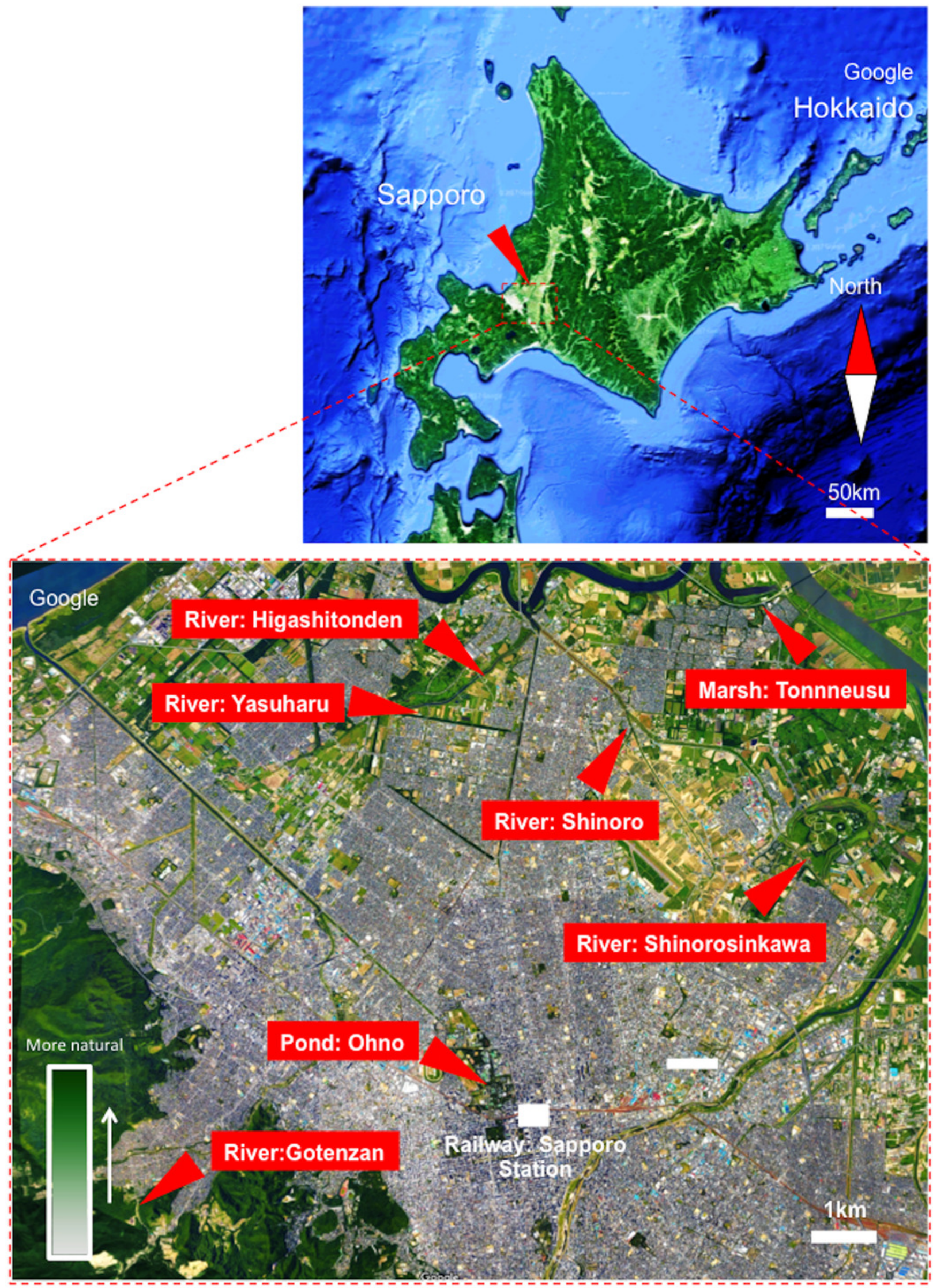
Figure 2

Representative images showing distinct morphological traits of damselflies and changes in the dominancy of different damselfly species at each sampling site. 

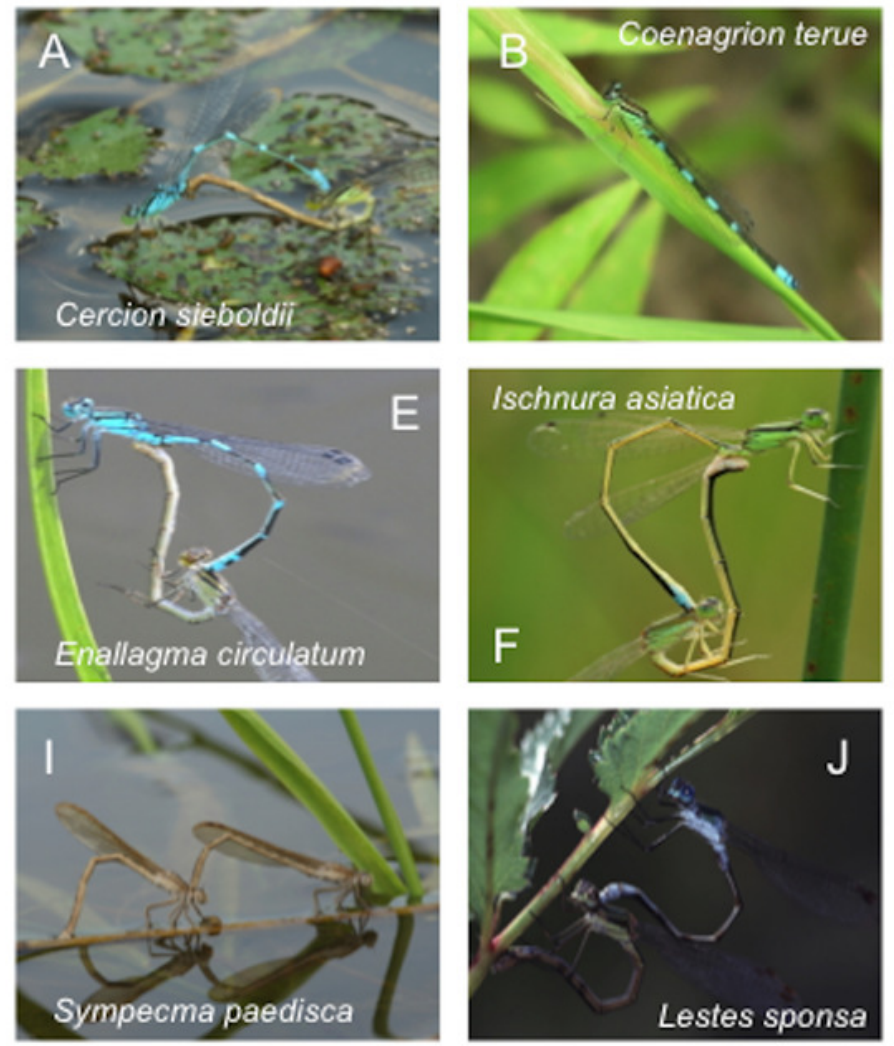
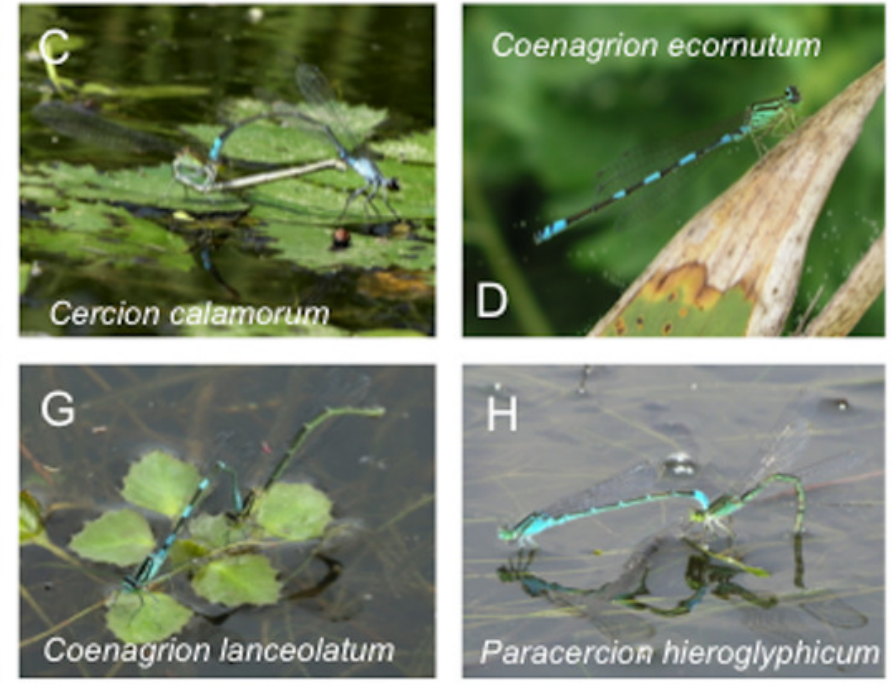

$\mathrm{K}$

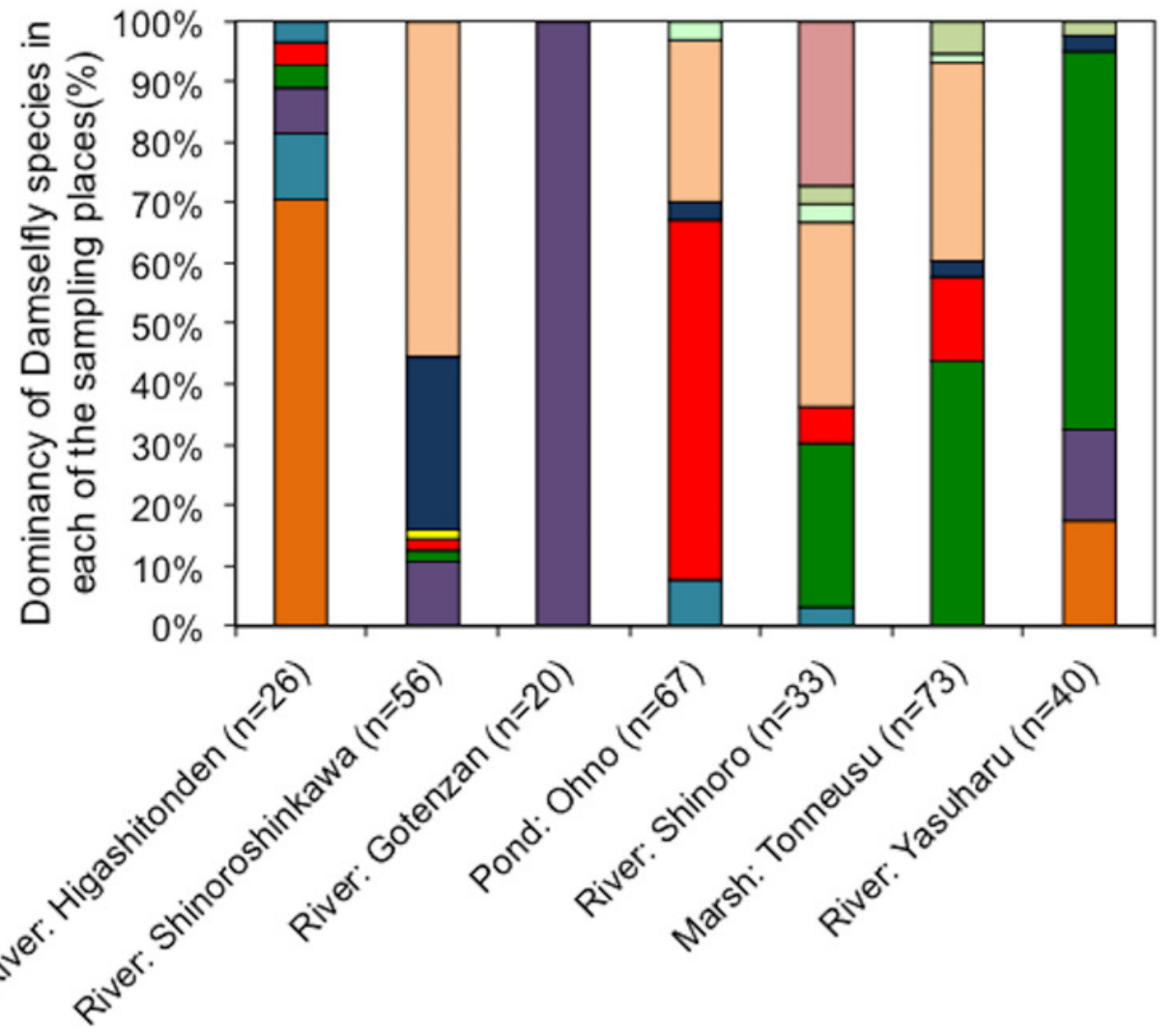

$\square$ Copera annulata

$\square$ Cercion sieboldii

$\square$ Coenagrion lanceolatum

-Enallagma circulatum

- Sympecma paedisca

Ischnura asiatica

- Cercion calamorum

- Paracercion hieroglyphicum

-Lestes sponsa

-Coenagrion terue

$\square$ Coenagrion ecornutum 
Figure 3

Collection of fecal materials from adult and larval damselflies and cultures. 


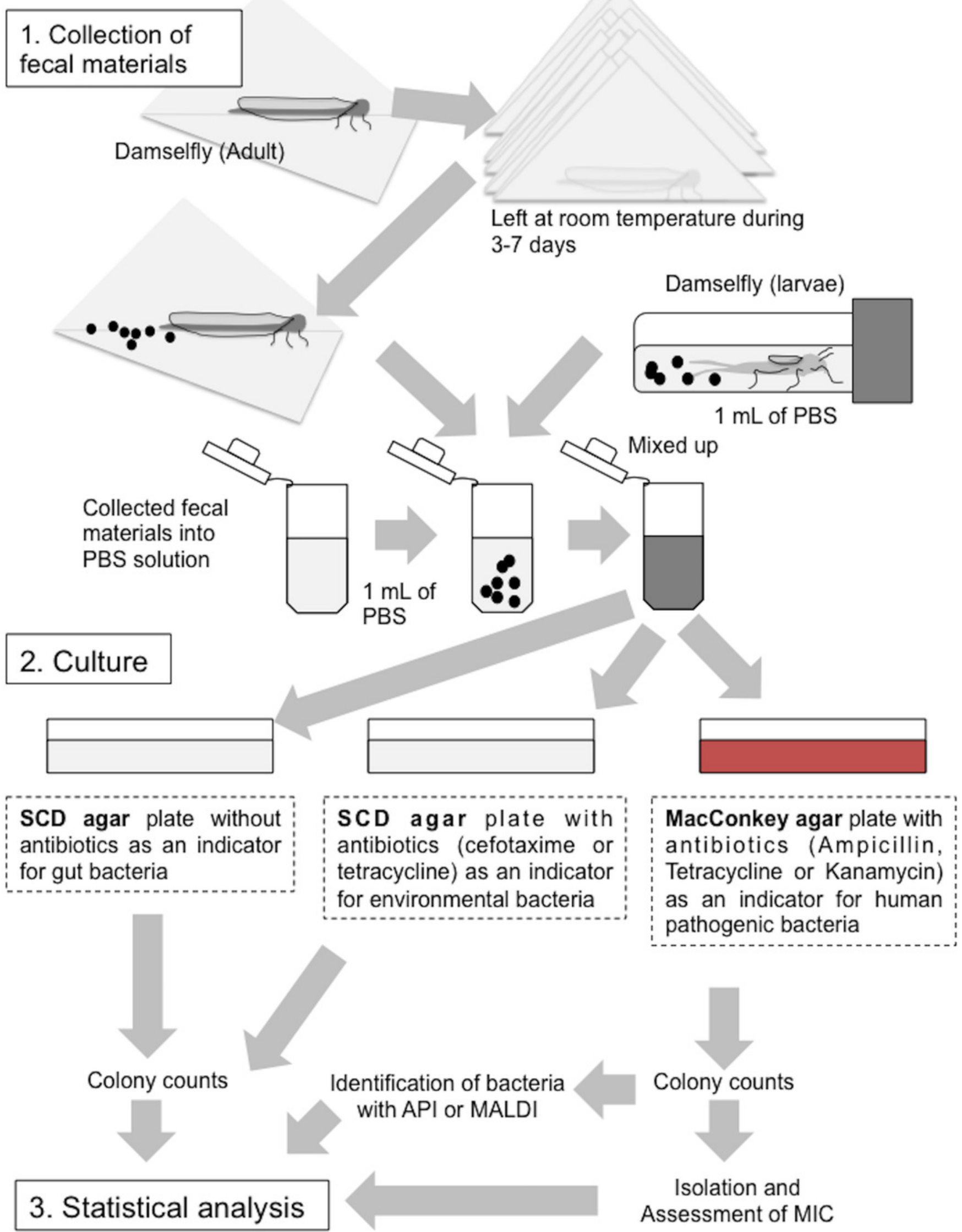


Figure 4

Bacterial load in fecal materials estimated following culture on SCD agar plates without antibiotics. 
A
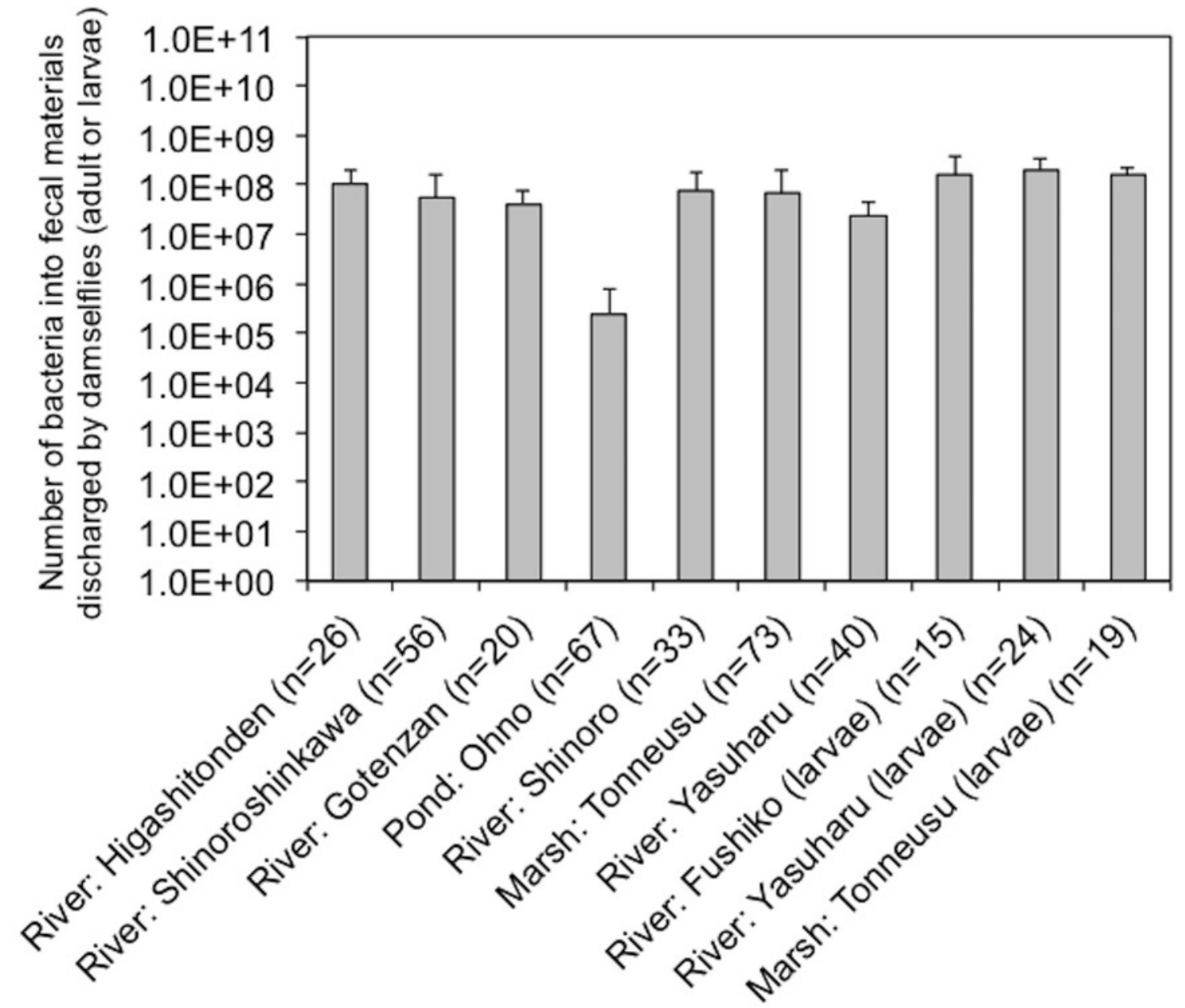

B

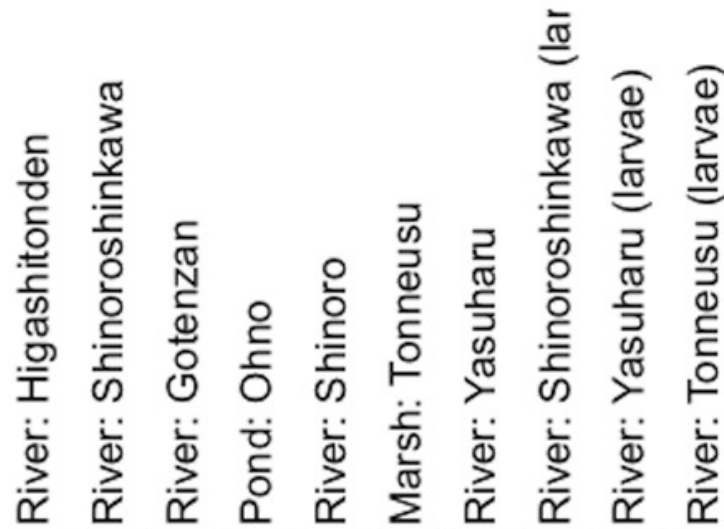

River: Higashitonden River: Shinoroshinkawa River: Gotenzan Pond: Ohno River: Shinoro Marsh: Tonneusu

River: Yasuharu

River: Shinoroshinkawa (larvae)

River: Yasuharu (larvae)

River: Tonneusu (larvae)

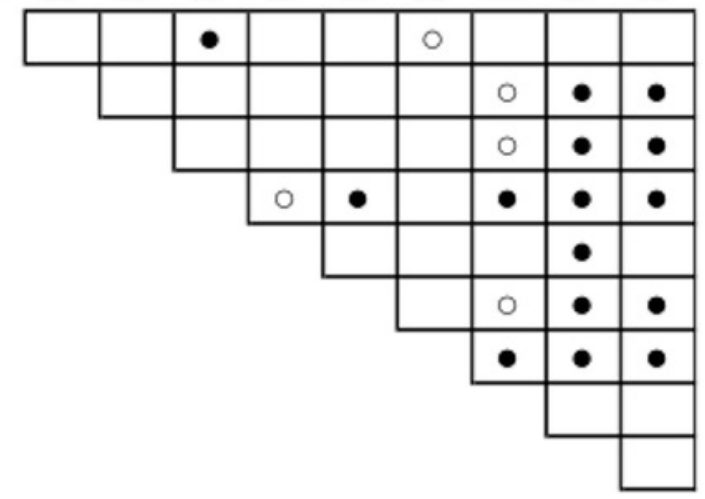


Figure 5

Association between total bacterial load (SCD agar plate without any antibiotics) or the prevalence of antibiotic-resistant bacteria (SCD agar plates with antibiotics and MacConkey agar plates with antibiotics) and environmental temperature. 
A

$\mathrm{SCD}-\mathrm{CFU} / \mathrm{mL}$ Lowest temperature Highest temperature SCD-Antibiotics Mc-Antibiotics SCD-MC-all antibiotics

\begin{tabular}{|c|c|c|c|c|c|}
\hline 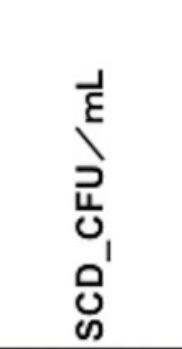 & 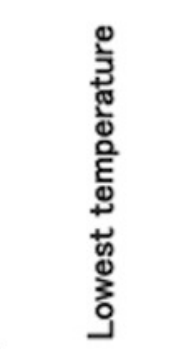 & 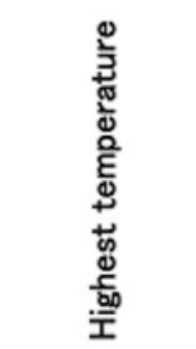 & 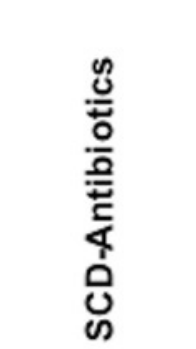 & 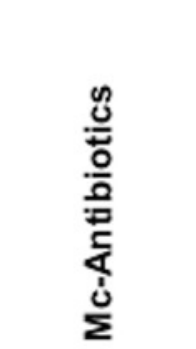 & 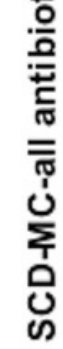 \\
\hline 1 & & & & & \\
\hline-0.677218 & 1 & & & & \\
\hline-0.590287 & 0.9448206 & 1 & & & \\
\hline-0.076713 & 0.1835471 & 0.1590746 & 1 & & \\
\hline-0.117589 & 0.152643 & 0.1508482 & 0.0448608 & 1 & \\
\hline-0.134409 & 0.2325643 & 0.2143927 & 0.7228348 & 0.7227521 & 1 \\
\hline
\end{tabular}

B

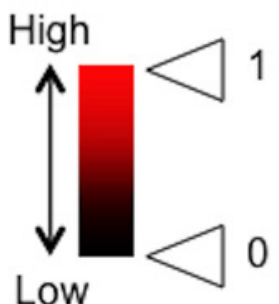

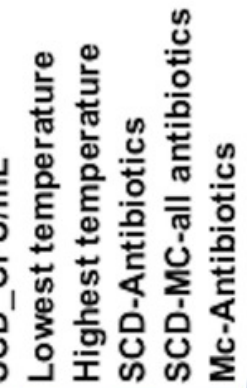
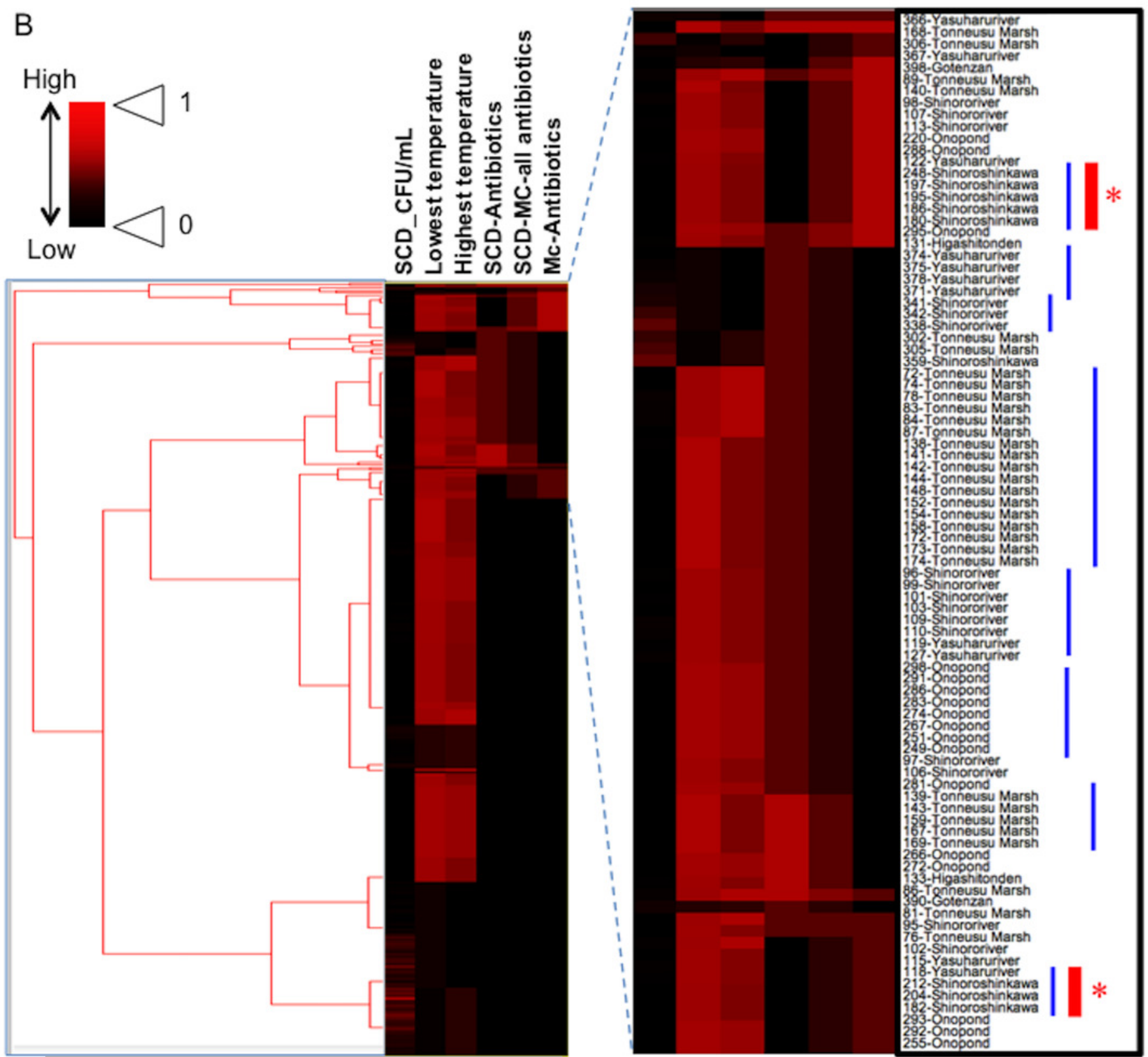
Figure 6

Prevalence of isolated strains from MacConkey agar plates with antibiotics at each of the sample location (\%).

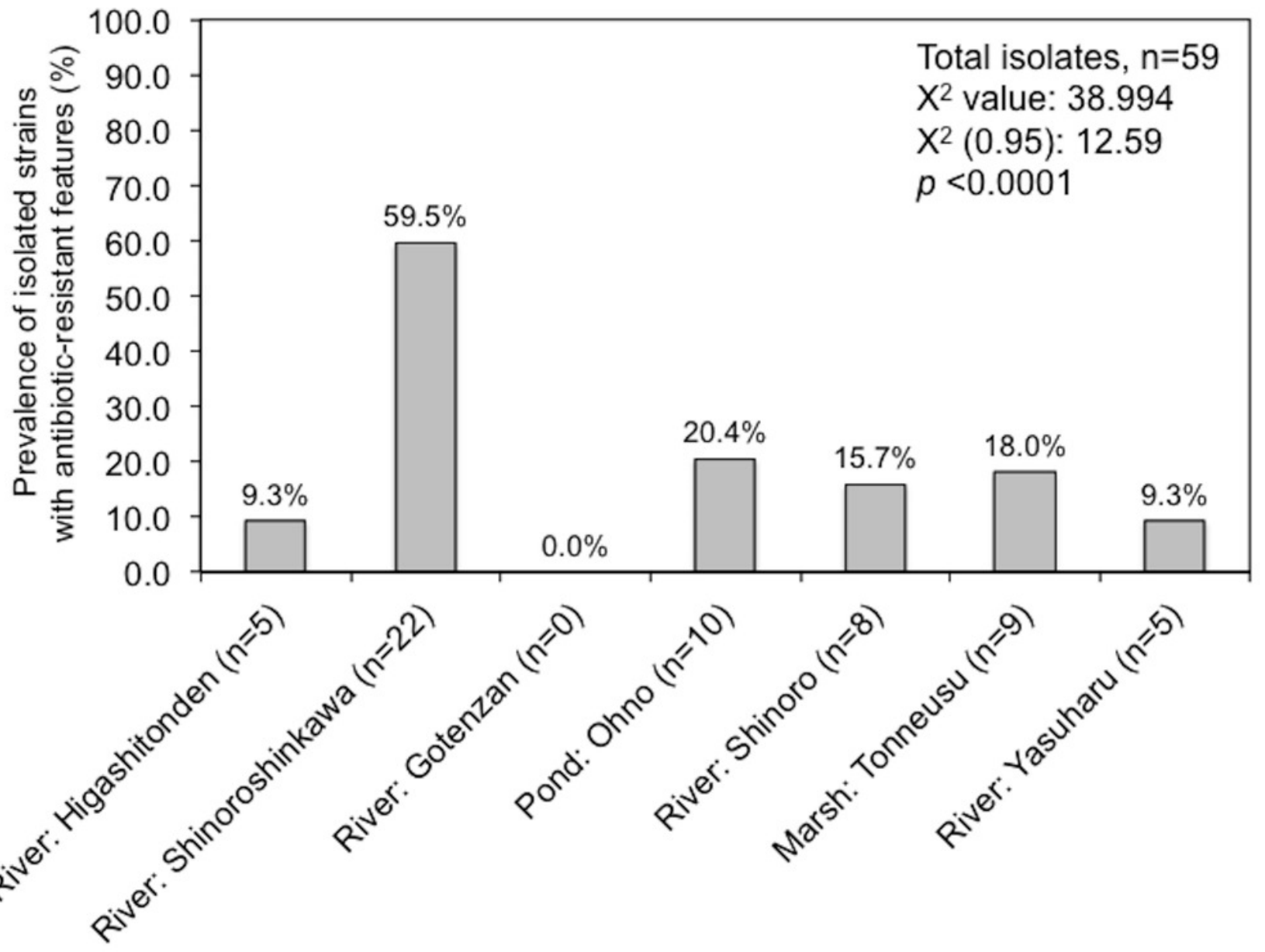


Figure 7

Comparison of the prevalence of antibiotic-resistant bacteria on SCD agar plates with that on MacConkey agar plates, and identification of representative antibiotic-resistant Enterobacterales, including MIC data. 
A

\begin{tabular}{|c|c|c|c|c|c|}
\hline [AMP] & [KAN] & [TET] & [CHL] & {$[\mathrm{CIP}]$} & [SPY] \\
\hline $\mathrm{MIC}_{50} \quad \mathrm{MIC}_{90}$ & $\mathrm{MIC}_{50} \quad \mathrm{MIC}_{90}$ & $\mathrm{MIC}_{50} \quad \mathrm{MIC}_{90}$ & $\mathrm{MIC}_{50} \quad \mathrm{MIC}_{90}$ & $\mathrm{MIC}_{50} \quad \mathrm{MIC}_{90}$ & $\mathrm{MIC}_{50} \quad \mathrm{MIC}_{90}$ \\
\hline
\end{tabular}

River: Higashitonden $(\mathrm{n}=5)$

River: Shinoroshinkawa $(n=22)$

\begin{tabular}{|cc|}
\hline$>128$ & $>128$ \\
128 & $>128$ \\
128 & $>128$ \\
$>128$ & $>128$ \\
$>128$ & $>128$ \\
128 & $>128$ \\
\hline
\end{tabular}

\begin{tabular}{|cc|}
\hline 1 & 1 \\
1 & 32 \\
1 & 1 \\
2 & 8 \\
1 & 2 \\
$<0.5$ & 2 \\
\hline
\end{tabular}

\begin{tabular}{|ll|}
\hline 2 & 2 \\
2 & 8 \\
2 & 4 \\
2 & 8 \\
1 & 4 \\
8 & 8 \\
\hline
\end{tabular}

\begin{tabular}{|cc|}
\hline 4 & 8 \\
4 & 16 \\
4 & 16 \\
8 & 16 \\
8 & 16 \\
8 & 16 \\
\hline
\end{tabular}

$\begin{array}{|cc|}<0.125 & <0.125 \\ <0.125 & 1 \\ <0.125 & 0.125 \\ <0.125 & <0.125 \\ <0.125 & <0.125 \\ 0.25 & 0.25\end{array}$

\begin{tabular}{|cc|}
\hline$>128$ & $>128$ \\
128 & $>128$ \\
$>128$ & $>128$ \\
128 & $>128$ \\
128 & $>128$ \\
128 & 128 \\
\hline
\end{tabular}

B

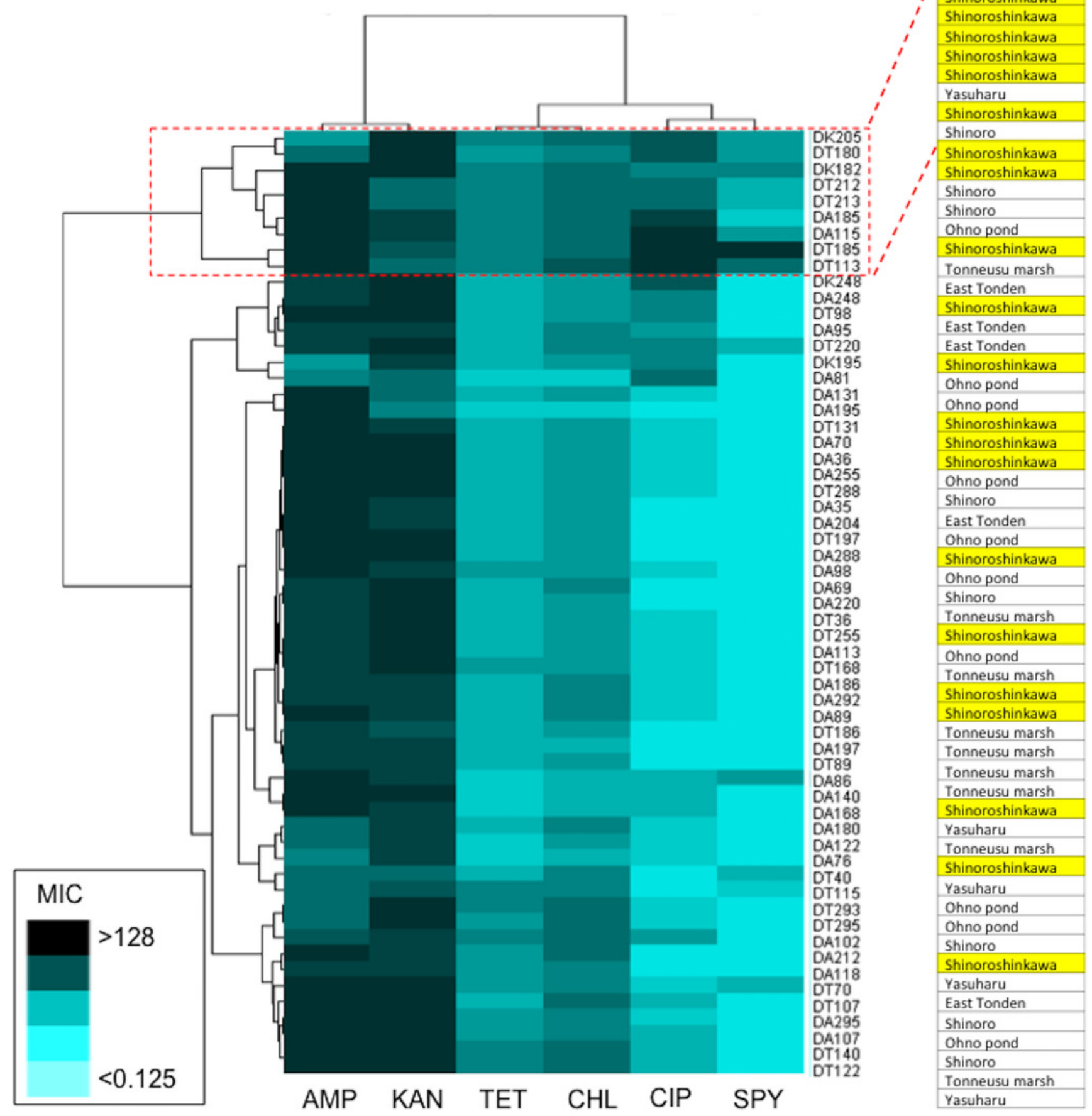

